\title{
Research on Accounting Talents' New Ability in the Context of Big Data
}

\author{
Wanyi Zhou, a, Jing $\mathrm{Xia}^{2, \mathrm{~b}, *}$ \\ ${ }^{1}$ Finance Department of Wuhan Textile University, Wuhan, Hubei 430200 \\ ${ }^{2}$ Finance Department of Wuhan Textile University, Wuhan, Hubei 430200 \\ a95252355@qq.com, b305093906@qq.com
}

Keywords: Big data, Accounting talent, New ability

\begin{abstract}
In the context of big data, accounting work is replaced by more and more information systems. Accountants in our country need to be adept at original data collection, analysis and cleaning as well as data mining modeling as a way to change the fact that our accountants only owns traditional accounting, financial and auditing knowledge. Thus, a completely new knowledge system including big data will come into being.
\end{abstract}

\section{Introduction}

With the advent of the era of big data, accountants are facing daunting challenges different from the past. As the accounting work is replaced by more and more information systems, accountants not only need to learn traditional accounting, finance and auditing, but also need to acquire some knowledge about accounting information system in the context of big data (Cheng Anlin, 2012). Due to the complexity of big data, such as original data collection, analysis and cleaning as well as data mining modeling, it means that accountants need more knowledge about big data, which should be taught in the undergraduate education, to realize the utilization and research of enterprises' big data accounting information system (Li Shuang, Tan Wenhao, 2011). Based on this, we conduct a study on the new ability required for the accountants in our country in the context of big data. That means accountants in our country need to assist management to be adept at original data collection, analysis and cleaning as well as data mining modeling as a way to change the fact that our accountants only owns traditional accounting, financial and auditing knowledge. Thus, a completely new knowledge system including big data will come into being.

\section{New Ability Required for Accountants in Our Country in the Context of Big Data}

Accounting education belongs to the traditional industry, but it needs to make corresponding changes to meet enterprises' needs in the context of big data (Teng Xiaomei, 2014). That means in the era of big data accountants need to assist management, requiring some knowledge about accounting system related to big data to meet enterprises' needs. If accountants only can account, they will be replaced by computer automatic accounts. Therefore, the ability to obtain information needed by management from complex information has become an essential skill that accountants need to master (Tong Chengsheng et al., 2014)

As shown in Figure 1, accountants need to assist management to be adept at original data collection, analysis and cleaning as well as data digging modeling as a way to serve enterprises through big data accounting system. That means they need to find data about financial management and analysis from complex information. This can be best explained by that firstly accounts need to collect tremendous original data which includes not only traditional vouchers, but also other data such as data in the industrial database, government tax database and statistics database. This requires accountants master some knowledge about database and connect the enterprise's database with other database. Secondly, accountants need to analyze data on the basis of original collected data, adopting the analysis approach of regression, typical case and demands to analyze tremendous original data to find abnormal fluctuations as a way to help management find and solve risks. 
Thirdly, accountants need to learn original data cleaning and then put the cleaned data into an accounting system of big data for accounting. That means the cleaned, true and reliable original data will be put into big data accounting system in order to prevent fraudulent and false data into the accounting system. Finally, accountants are required to do data digging modeling analysis for the real data entering the big data accounting system. This means an extremely high requirement for accountants, higher than original data analysis. We can help management understand the risks and discover the profits of enterprises through the methods of clustering and dispersing of data digging modeling analysis.

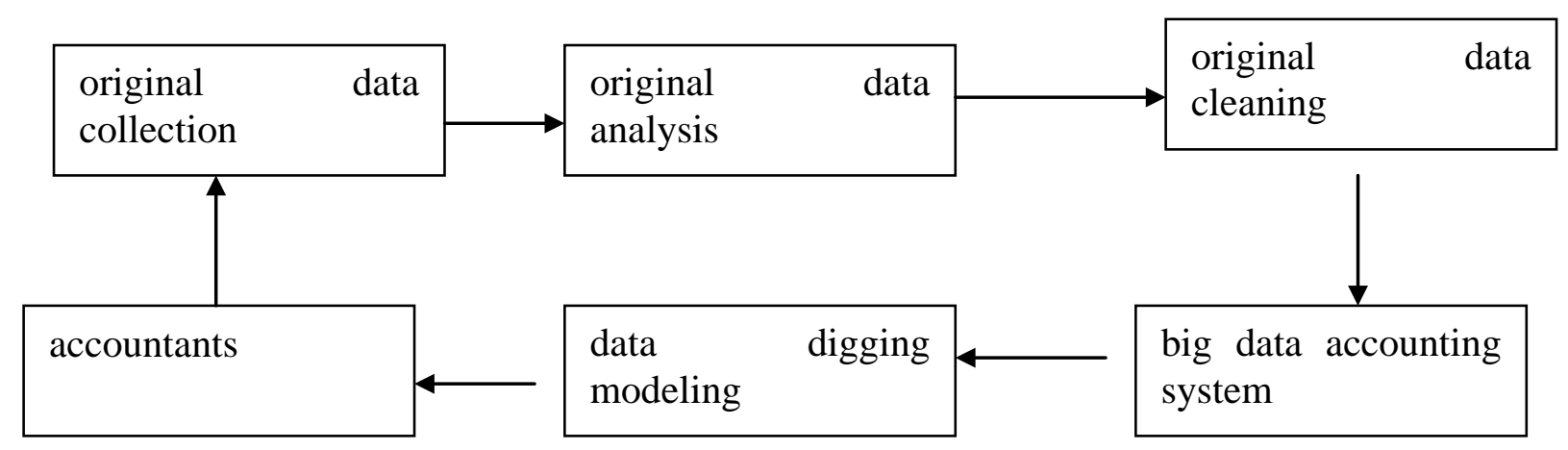

Figure 1 Accounting Operation System of Dig Data

\subsection{Accountants need to master the skills of original data collection}

Accounting data collection refers to various certificates produced by other units or inside the enterprises experiencing numerous business, financial and production activities. These certificates need to be properly formatted to convert into computer information that can be recognized by big data accounting system. Accountants are required to understand some basic knowledge of big data computing, such as IAAS, PAAS and SAAS and convert the original data through computing service virtual software of big data (Zhao Caixia, 2016). Therefore, it is necessary to add the method of data collection in the accountants training.

Currently, several methods can be adopted to collect data through course learning: (1) Accountants learn the data export of accounting information system to collect data. Accountants directly make use of the data export offered by information management system to complete the corporate management system collection. (2) Accountants complete data collection by the common data processing software. For example, accountants choose to use Access, SQL Server with powerful function of data import and conversion to finish data collection. (3) Accountants learn to use accounting software to finish data collection. Accounting data collection can be completed by some enterprises' financial software and accounting data collection and analysis software. (4) Accountants use some specialized program interface to complete data collection. If there is a huge difference between accounting data provided by service units and data structure offered by the data processing software, accountants are required to prepare the interface program to complete the data collection. This method requires that accountants are good at big data computing and processing.

\subsection{Accountants need to master the skills of original data analysis}

In the context of big data, accountants are required to collect the corresponding original data and then further analyze it in order to provide managers with appropriate information of decision-making. The analysis of original data also means accountants need to estimate the financial risk. For example, using the big data systems digs the data fluctuations and discovers problems in the data fluctuations compared with industries and other enterprises. However, the current basic qualifications of accountants are relatively low, and most of them can only make accounting. This makes it difficult to meet the requirements of management's financial risk estimation in the context of big data.

Currently, several methods can be learned through course learning to analyze data: (1) Method of 
regression analysis. Accountants learn to use the regression analysis method to understand factors affecting business, finance or production and then propose proper strategies for improvement. For example, when the cost of production and operation of the original data rises, accountants can discover that the operation cost rise results from the increase of the prices of ram materials or labor costs through regression analysis. If the regression analysis does not been adopted, wrong conclusions may be reached that the rise of operation is only due to the increase of the prices of ram materials. (2) Method of typical case analysis. Accountants learn to use the typical case analysis to find the measures taken by other enterprises when similar problems take place, which will help management in the enterprises solve the current problems. For example, when major shareholder tunneling takes place in many listed companies, which directly reflects in the original data of stock price and the proportion of shareholding, accountants are supposed to discover this problem and directly consult measures already taken by enterprises and make recommendations to management through the original data analysis. (3) Method of demand analysis. Accountants can use the method to help enterprises find out whether there is raw material shortage, whether market needs some kind of product and whether a research can meet the enterprises' needs. As the most-needed method for management, it can help enterprises solve many problems. For example, when accountants find raw material shortage in the first place and report it to management, the shortage time will be greatly reduced, the problem can be solved immediately and raw materials will be supplied for production.

\subsection{Accountants should be adept at original data cleaning}

Hard to confirm the truth and reliability of original data, accountants should be adept at original data cleaning to reduce the risks of problematic data in big data accounting system, which may cause problems in data analysis and influence the final decision of management. For instance, when buyers and suppliers fraudulently raise the purchase price, enterprises will have to suffer the loss if accounting data directly enter the accounting system without cleaned, thus raising the risk of fraud in enterprises and making enterprises fail in risk control. Accountants are required to learn some knowledge involving data analysis, mode conversion and data verification in the process of data cleaning, which can be specified as followed:

Firstly, it is the data analysis knowledge. The knowledge is not equal to the original data analysis, which means analyzing the fluctuation and ratio of original data so as to find the risk as soon as possible and adopt the corresponding management methods. However, the analysis knowledge in original data cleaning means analyzing the format types of data, such as the collected financial data, sale data, and field types and meaning of production data. In this way, accountants can recognize the problematic data in the original data which may have the risk of fraud or result from some mistakes.

Secondly, it is the mode conversion knowledge. Accountants should master the mode conversion knowledge of how to map the source data into target data model. More specifically, it includes converting the unstructured data like field and file into computer language and comparing these data with structured financial data to help accountants find risks. For example, accountants can combine the payroll, the unstructured data forms on the education background and study time of the employees into a multidimensional form to help them find whether there are salary frauds.

Thirdly, it is the data verification knowledge. That means accountants analyze and evaluate the converted data to learn whether there are problematic data in conversion and then screen them out. For example, when a mode is converted, a data set may be divided into several data forms or many data forms may be combined into a multidimensional form, which may make the primary key, relevant numeric and key numeric outside the sub-table inconsistent with one another and form the mismatched record. Thus the analysis by accountants may be inaccurate and the decision by management will be greatly affected.

Finally, data reflow knowledge. In the process of data verification, errors and frauds may be inconspicuous and one-time cleaning cannot find all the errors, which requires accountants to master the data reflow knowledge, cleaning data repeatedly to improve data quality and finally enter the big data accounting system. For instance, after buying at a higher price than the purchase price, 
raw material buyers collude with purchasing managers to examine and approve the purchase fraudulently. In that case, accountants may not find errors in the first data cleaning, because raw material price may fluctuate in the normal market environment. However, when making a second cleaning, accountants can compare with similar enterprises and offers by other suppliers to find the fraud.

\subsection{Data mining modeling analysis capability}

Demands for accountants are becoming increasingly higher in the context of big data, especially in management. True and reliable data are acquired after data enter the big data accounting system and accountants are required to dig and model these data to find the current major risk in enterprises. The risk is more specific than those in original data process, such as production risk, financial risk and marketing risk that must be considered by management. Thus accountants are required to learn the data digging so as to dig significant information from the two-dimensional data forms in accounting system. To be specific, accountants can learn the data digging modeling analysis knowledge as followed.

Firstly, it is the clustering digging modeling analysis knowledge. Clustering is grouping similar data like features, risks and contents and more groups show more consistent data. Accountants need to master the method to classify the financial and non-financial data, thus finding the different data in this kind of data. For example, accountants can find the purchasing price of a batch of products is much higher than that of other batches or a loan contract is made up by other loans through clustering analysis. The analysis method can dig out special sample that happens to be the risk of enterprises and needs to be further analyzed and reported to the management by accountants.

Secondly, it is the outlier data digging modeling analysis knowledge. The method is drawing all the data and find a significant deviation from the data. Accountants need to master the method to analyze the discrete data as a specific problem and make them the breakthrough for management to develop enterprises. If accountants find the profits of a newly developed product are much higher than those of other products, that means the product is recognized by the market and accountants need to advise the management to expand its production scale and continues to develop to avoid imitation. Or if accountants find a supplier buys many raw materials as a package at a price much lower than buy separately or other suppliers, that means buying many raw materials as a package can be used in buying from these suppliers. Thus accountants can gain big profits through outlier data analysis.

\section{Conclusion}

Under the urgent demand of developing our accounting talents in the context of big data, accountants in our country need to be adept at original data collection, analysis and cleaning as well as data mining modeling as a way to change the fact that our accountants only owns traditional accounting, financial and auditing knowledge. Thus, a completely new knowledge system including big data will come into being.

\section{References}

[1] Cheng Anlin. Research on training mode of excellent accounting talents [J]. Finance and Accounting Monthly, 2011(11): 91-93.

[2] Li Shuang, Tan Wenhao. The training of accounting talents based on accounting practice teaching: Discussion on the construction of accounting discipline [J]. Communication of Finance and Accounting, 2011(11): 154-157.

[3] Teng Xiaomei. Research on the connotation of excellent accounting talents in applied undergraduate colleges [J]. Communication of Finance and Accounting, 2014(9): 121-125.

[4] Tong Chengsheng, Xu Sulan, Li Kouqing, Liang Shuping. Research on training mode of accounting talents in Chinese enterprises [J]. The Accounting Research, 2014(9): 13-20. 
[5] Zhao Caixia, Wu Du, Lei Guoqiong. The thought and method of the training of accounting information management talents in big data era [J]. Chinese Management Information. 2016(3): 34-36. 